\title{
O ENSINO SUPERIOR DE QUÍMICA: REFLEXÕES A PARTIR DE CONCEITOS BÁSICOS PARA A QUÍMICA ORGÂNICA
}

\author{
Salomão Bento de Vasconcelos Rodrigues, Dayse Carvalho Da-Silva* e Ana Luiza de Quadros \\ Departamento de Química, Universidade Federal de Minas Gerais, Av. Antônio Carlos, 6627, 31270-901 Belo Horizonte - MG, Brasil
}

Recebido em 6/3/11; aceito em 14/6/11; publicado na web em 5/8/11

\begin{abstract}
COLLEGE-LEVEL CHEMISTRY EDUCATION: REFLECTIONS BASED ON CORE ORGANIC CHEMISTRY CONCEPTS.
We live in a context in which knowledge develops continuously and rapidly. This generates a social dynamics that demands constant adaptation from those living in society and also from educational institutions. Education for this new society needs to be rethought. Universities, anchored in tradition, still use a transmission/reception model of education. A data-collecting instrument applied to undergraduate chemistry students at the end of the course in organic chemistry investigated some concepts essential to the education of a chemist, such as interatomic and intermolecular interactions and Lewis structure. We observed that students have difficulty dealing with these concepts, and we believe that this is related to the type of class they had/have and to the way the concepts are presented in the college textbooks.
\end{abstract}

Keywords: higher education; essential concepts; Organic Chemistry.

\section{INTRODUÇÃO}

Com o visível crescimento das pesquisas na área de Educação Química, tornam-se mais perceptíveis os resultados do ensino que fazemos, em todos os níveis. Ensinar e aprender os conceitos centrais da Química tem sido o desafio de professores da área e uma preocupação no meio acadêmico, que não só ensina Química, mas também forma professores para tal.

Resultados nada promissores, oriundos dos instrumentos oficiais de avaliação do ensino (Exame Nacional do Ensino Médio - ENEM, Exame Nacional de Desempenho do Estudante - ENADE, vestibular e outros instrumentos) e das pesquisas em educação, fazem surgir novas demandas nas políticas educacionais. A Lei de Diretrizes e Bases da Educação Nacional promulgada em 1996, ${ }^{1}$ e o Edital n ${ }^{\circ}$ 04/97² da Secretaria de Educação Superior do MEC estabelecem que os currículos do Ensino Superior devam ser revistos. Intensificam-se os questionamentos sobre a massiva transmissão de informações e de conhecimentos específicos frente à velocidade com que as inovações científicas e tecnológicas vêm surgindo. Há o entendimento de que é mais produtivo ensinar o estudante a buscar informações e analisá-las com um senso crítico, do que meramente transmitir essas informações.

A Química faz parte deste contexto. Para a implementação de um ensino que atenda às demandas sociais foram criadas as Diretrizes Curriculares para os Cursos de Química, ${ }^{3}$ as quais orientam para uma formação ampla e multidisciplinar, de um profissional autônomo, criativo, que saiba atuar em equipe, além de outras necessidades formativas. Porém, acreditamos que a mudança curricular não será suficiente para a melhoria do Ensino Superior. Também é necessário que haja engajamento e mudança de postura dos profissionais docentes do Ensino Superior e dos estudantes, além da melhoria dos materiais didáticos.

Neste trabalho dirigimos nosso olhar para o Ensino Superior, investigando a aprendizagem de alguns conceitos considerados importantes para a continuidade de estudos em Química Orgânica, em estudantes de graduação.

\footnotetext{
*e-mail: daysecsm@yahoo.com.br
}

\section{VISITANDO A LITERATURA}

Muitas críticas têm sido feitas ao ensino universitário como um todo e, também, aos cursos de licenciatura. Schnetzler ${ }^{4}$ problematiza a separação entre os conteúdos específicos e as disciplinas de cunho pedagógico em tais cursos. Esta pesquisadora afirma que não ocorre um diálogo entre estes dois domínios, com consequências para o professor em formação. Consideramos que deixar para o estudante a responsabilidade de associar os conhecimentos específicos das diversas disciplinas do campo da Química com os conhecimentos pedagógicos das disciplinas didáticas é, no mínimo, irresponsabilidade. Parece que o professor universitário, muitas vezes, valoriza o conteúdo mais do que o próprio estudante e a sua aprendizagem.

Os professores universitários, ligados aos departamentos e
institutos das chamadas ciências exatas, mantêm, de alguma
forma, a atual convicção de que basta uma boa formação
científica básica para preparar bons professores para o
ensino médio e fundamental, enquanto os professores da
formação pedagógica percebem a falta de uma visão clara
e mais consistente dos conteúdos específicos, por parte dos
licenciados em fase final de sua formação, impedindo a reela-
boração pedagógica para torná-los disponíveis e adequados
à aprendizagem de jovens e adolescentes. ${ }^{5}$

Este tipo de ensino é caracterizado como técnico, já que pensa no ato profissional como a solução de problemas por simples aplicação da teoria ou do conhecimento, considerando que apenas o conhecimento específico basta para o profissional exercer sua função.

Conforme já citado, a Lei de Diretrizes e Bases de Educação Nacional (Lei 9.394/96) ${ }^{1}$ e o Edital n ${ }^{\circ} 04 / 97^{2}$ da Secretaria de Educação Superior do MEC estabelecem uma reformulação nos currículos dos cursos superiores, em função das novas demandas e realidades sociais. As Diretrizes curriculares para o Ensino Superior trazem 
Quadro 1. Livros de Química Geral e Química Orgânica considerados

\begin{tabular}{|lll|}
\hline Disciplina & Título & Autores \\
\hline \multirow{2}{*}{ Química Geral } & Princípios de Química $^{6}$ & Atkins, P. e Jones, L. \\
& Química Geral $^{7}$ & Russel, J. \\
& Química: Um curso universitário ${ }^{8}$ & Mahan, B. \\
\hline \multirow{2}{*}{ Química Orgânica } & Química Orgânica ${ }^{9}$ & Solomons, T.W. e Fryhle, C.B. \\
& March's Advanced Organic Chemistry ${ }^{10}$ & Smith, M. e March, J. \\
\hline
\end{tabular}

sugestões, apontam caminhos para esta reformulação e traçam novas perspectivas. Para os cursos de Química, as principais habilidades a serem desenvolvidas durante o curso de graduação são: ${ }^{3}$

a) para o bacharelado: buscar uma formação ampla e multidisciplinar fundamentada em sólidos conhecimentos de Química; desenvolver metodologia e senso de responsabilidade que lhe permita uma atuação consciente; exercitar sua criatividade na resolução de problemas; trabalhar com independência; desenvolver iniciativas e agilidade no aprofundamento de seus conhecimentos científicos; aprender a tomar decisões, levando em conta os possíveis impactos ambientais ou de saúde pública.

b) para o licenciado: adquirir conhecimentos sólidos do conteúdo de Química no nível do Ensino Médio; adquirir conhecimentos de Química superior que permitam uma visão da importância dos tópicos que esteja ensinando no contexto geral da Química e outras áreas afins, além da possibilidade de ingressar em cursos de pós-graduação; adquirir conhecimento de disciplinas afins (Física, Matemática e Biologia) como instrumento de compreensão e utilização da Química; ser desafiado a trabalhar com criatividade na resolução de problemas, trabalhar com independência e em equipe, transmitir claramente conteúdos e dificuldades, e desenvolver iniciativas e agilidade na atualização e aprofundamento constante de seus conhecimentos.

Podem-se notar semelhanças entre algumas habilidades sugeridas para os cursos de bacharelado e licenciatura, tais como a criatividade na resolução de problemas, a independência de trabalho e a busca pelo conhecimento. Espera-se que estas habilidades, atreladas aos conteúdos específicos de Química, garantam a formação de um bom profissional.

No que se refere aos conteúdos específicos, os cursos de Licenciatura em Química possuem, na grade curricular, uma carga horária de disciplinas voltadas a eles normalmente superior ao exigido. Isto configura ênfase ao conhecimento químico, com um nível de aprofundamento significativo, na tentativa de fornecer uma formação mais sólida neste campo. Entretanto, as diretrizes para os cursos de Licenciatura em Química apontam para a necessidade de uma formação mais ligada ao "ser professor" de Química, na qual são necessários os conteúdos específicos, mas com a necessidade de uma carga horária maior nas disciplinas de prática pedagógica e estágio. Considerando a rede mundial de informação e comunicação - internet - e as diversas formas em que o conhecimento está disponibilizado, há o entendimento de que o papel de transmissor de informações não cabe mais ao professor. Seu papel é mais amplo e deve priorizar o "aprender a aprender", auxiliando o estudante na busca, seleção e análise das informações disponíveis.

Como tarefa de todo professor, tanto de Ensino Superior quanto da Educação Básica, está a seleção do que é central no conteúdo a ser ensinado e, portanto, não pode ser subestimado e aquilo que é complementar.

Reconhecendo a importância de estudo dos conteúdos abordados na área de Química Orgânica, procuramos identificar a concepção que estudantes de graduação apresentam sobre os conceitos de ligações químicas, interações intermoleculares e estrutura de Lewis.

\section{METODOLOGIA}

O trabalho consistiu, inicialmente, de entrevista informal com duas professoras do setor de Química Orgânica do Departamento de Química (DQ) do Instituto de Ciências Exatas da Universidade Federal de Minas Gerais (UFMG), para identificar os conceitos químicos considerados pré-requisitos para que o estudante de graduação possa transitar bem pelas disciplinas de Química Orgânica. Entre os diversos conceitos necessários, selecionamos ligações químicas, interações intermoleculares e estrutura de Lewis, devido à importância dos mesmos para o entendimento não apenas da Química Orgânica, mas para a Química como um todo.

Conhecendo estes conceitos, construímos um instrumento de coleta de dados - questionário - que foi aplicado a duas turmas que finalizavam a disciplina Química Orgânica I, ofertada pelo DQ, no segundo semestre de 2009. Esse instrumento continha uma única questão dividida em três subitens. A análise das respostas dos estudantes fez com que dirigíssemos o nosso olhar também para os livros didáticos apontados como bibliografia básica para as disciplinas de Química Geral e Química Orgânica I, nesse mesmo semestre. Os livros consultados como bibliografia de Química Geral são apresentados no Quadro 1.

As turmas investigadas foram escolhidas aleatoriamente entre aquelas cujos professores se mostraram disponíveis em conceder um tempo de suas aulas para a aplicação do questionário. A primeira turma, denominada turma $\mathrm{A}$, consistia de 25 alunos do $3^{\circ}$ período do curso de farmácia da UFMG. A segunda turma, denominada turma B, consistia de 13 alunos do $3^{\circ}$ período do curso de Química da UFMG. Nestas turmas, o tempo usado pelos estudantes para responder ao questionário não ultrapassou $15 \mathrm{~min}$. Na turma $\mathrm{A}$, os alunos se mostraram mais dispersos no início, mas se concentraram após poucos minutos. Na turma $\mathrm{B}$, os estudantes foram bem receptivos desde o início e responderam de forma concentrada e dedicada.

\section{RESULTADOS E DISCUSSÃO}

A questão proposta apresentava a representação de uma estrutura química que deveria ser analisada pelos estudantes. Os três subitens da questão abordavam, em ordem, questionamentos relacionados à ligação química, interação intermolecular e estrutura de Lewis. Para todos os itens da questão proposta, a estrutura a ser analisada está representada na Figura 1.<smiles>CCC(C)Cl</smiles>

Figura 1. Estrutura sobre a qual foi realizada a questão proposta 
A seguir, os dados obtidos para cada um dos subitens são apresentados.

\section{Ligações químicas}

O primeiro item da questão explorava os tipos de interações interatômicas presentes na estrutura apresentada. Esperávamos que os estudantes identificassem as ligações covalentes e a ligação iônica, formada entre o núcleo positivo do nitrogênio quaternário piridínico e o ânion cloreto. Dirigimos o nosso olhar tanto para as respostas dos estudantes quanto para os livros didáticos.

\section{As respostas dos estudantes}

Nas duas turmas houve identificação de ligações covalentes e iônicas. Entretanto, alguns alunos adotaram a classificação de ligações simples e duplas. A Tabela 1 mostra as respostas obtidas.

Tabela 1. As ligações químicas presentes na estrutura, segundo os estudantes

\begin{tabular}{lcc}
\hline Respostas & Turma A & Turma B \\
\hline Covalente & $23(92 \%)$ & $12(92 \%)$ \\
Iônica & $19(76 \%)$ & $10(77 \%)$ \\
Simples e Duplas (não identificou como covalente) & $2(8 \%)$ & $2(15 \%)$ \\
\hline
\end{tabular}

Para a ligação covalente, os estudantes mostraram bom desempenho, pois apenas dois em cada uma das turmas não usaram esta classificação, preferindo as denominações de "simples e duplas", o que não nos permite identificar se eles têm o conhecimento de ligação covalente. Para a ligação iônica, a identificação não foi realizada por pouco mais de $20 \%$ dos estudantes de ambas as turmas. Acreditamos que isto tenha ocorrido pelo fato de que muitos deles estão acostumados a reconhecer a ligação iônica apenas entre íons monoatômicos, como acontece em alguns sais inorgânicos. O cloreto de sódio é um exemplo clássico, presente em todos os livros, ao se tratar de ligação iônica. Julgamos que, se os estudantes realmente tivessem entendido que a ligação iônica é a atração entre dois íons, independente de eles serem íons mono ou poliatômicos, conseguiriam reconhecê-la mesmo em uma molécula orgânica complexa, como foi o caso. Pelas respostas obtidas, podemos afirmar que alguns alunos acreditam que na Química Orgânica, as ligações iônicas não acontecem.

\section{As ligações químicas nos livros didáticos}

Nosso olhar para os livros didáticos indicou que todos os livros consultados apresentam as ligações químicas como sendo iônicas ou covalentes. Os livros analisados concordam sobre a afirmação de que as ligações covalentes são o compartilhamento de elétrons por diferentes átomos. Elas podem, ainda, ser classificadas em polares ou apolares, dependendo da eletronegatividade dos átomos envolvidos e, em simples, duplas ou triplas (ou até mesmo denominadas sigma ou pi, de acordo com os orbitais envolvidos). Ao definir ligação iônica, os livros também concordam ao afirmarem que se trata de uma atração eletrostática de íons com cargas opostas. Entretanto, Atkins e Jones ${ }^{6}$ fazem uma ressalva ao afirmarem que a interação entre íons, ou seja, a interação iônica é o mesmo que ligação iônica. Esta ressalva é importante, pois evidencia um ponto que não é claro em outros livros. A ligação iônica é normalmente classificada como uma interação entre espécies que contêm apenas 1 átomo, mas isto só será um bom modelo se os íons que estão interagindo forem monoatômicos, tanto que na maioria dos livros o $\mathrm{NaCl}$ é usado como exemplo para a ligação iônica. Porém, quando estes átomos já estão ligados covalentemente a outros, o íon resultante é poliatômico, ou um íon molecular, como o da estrutura proposta na questão. Para os estudantes a dúvida pode estar no fato desta interação ocorrer entre dois íons monoatômicos ou entre um íon monoatômico e um poliatômico. De qualquer forma, ocorre uma interação entre íons, sejam eles oriundos de íons mono ou poliatômicos, e esta interação iônica, como afirmaram Atkins e Jones, ${ }^{6}$ pode ser chamada de ligação iônica.

\section{Interações intermoleculares}

O segundo item da questão visava avaliar os conhecimentos sobre as interações intermoleculares existentes entre espécies cuja estrutura representada na Figura 1 poderia formar. Esperava-se que eles reconhecessem a presença de ligações de hidrogênio, interações dipolo-dipolo, interações de London e as interações íon-dipolo, sem necessariamente indicar entre que partes das moléculas a interação poderia ser formada. Esta foi, sem dúvida, a parte mais delicada da investigação.

\section{As respostas dos estudantes}

Ao aplicarmos o instrumento de coleta de dados, observamos que os estudantes forneceram respostas diversas para uma única interação. As respostas que se referiam a um mesmo tipo de interação, apesar de nomenclaturas diferentes, foram agrupadas em uma mesma categoria. Desta forma, seis categorias foram construídas: ligações de hidrogênio, interações dipolo-dipolo, interações de London, interações íon-dipolo, interações íon-íon e interações alternativas. Estes resultados são apresentados na Tabela 2 .

Tabela 2. As interações presentes na estrutura, segundo os estudantes

\begin{tabular}{llcc}
\hline Categorias & Respostas obtidas & Turma A & Turma B \\
\hline Ligação de & Ligação de hidrogênio & $16(64 \%)$ & $8(62 \%)$ \\
hidrogênio & Total de respostas da categoria & $16(64 \%)$ & $8(62 \%)$ \\
\hline \multirow{4}{*}{ Dipolo-dipolo } & Dipolo-dipolo & $18(72 \%)$ & $6(46 \%)$ \\
& Dipolo permanente & $2(8 \%)$ & $3(23 \%)$ \\
& Dipolo-dipolo permanente & $1(4 \%)$ & $1(8 \%)$ \\
& Total de respostas da categoria & $21(84 \%)$ & $10(77 \%)$ \\
\hline \multirow{4}{*}{ Forças de } & Dipolo induzido & $1(4 \%)$ & $5(38 \%)$ \\
& Dipolo induzido - dipolo instantâneo & $1(4 \%)$ & $1(8 \%)$ \\
& Dipolo permanente - dipolo induzido & $3(12 \%)$ & $1(8 \%)$ \\
& Dipolo induzido - dipolo induzido & $1(4 \%)$ & - \\
& van der Waals & $1(4 \%)$ & $2(15 \%)$ \\
& Total de respostas da categoria & $7(28 \%)$ & $9(69 \%)$ \\
\hline \multirow{2}{*}{ Íon-dipolo } & Íon - dipolo & $8(32 \%)$ & $5(38 \%)$ \\
& Total de respostas da categoria & $8(32 \%)$ & $5(38 \%)$ \\
\hline \multirow{2}{*}{ Alternativas } & Íon-íon & $1(4 \%)$ & $2(15 \%)$ \\
& Total de respostas da categoria & - & $1(8 \%)$ \\
\hline \multirow{2}{*}{ Ín-íon } & Iônica & $3(12 \%)$ & - \\
& Interação eletrostática & $2(8 \%)$ & - \\
& Total de respostas da categoria & $6(24 \%)$ & $2(15 \%)$ \\
\hline
\end{tabular}

Se considerarmos as respostas escritas como o saber dos estudantes sobre o assunto, podemos afirmar que as interações intermoleculares ainda não são devidamente conhecidas ou entendidas por eles. A principal dificuldade percebida parece estar relacionada à nomenclatura dos tipos de interação presentes entre espécies cuja estrutura está representada na Figura 1. Como geralmente se utilizam palavras compostas para mencionar uma interação intermolecular (dipolodipolo, dipolo induzido-dipolo induzido etc.), alguns estudantes se 
sentem livres para combinar palavras, sem realmente refletir sobre a interação que estão propondo. Exemplo disto é a resposta elaborada por um aluno, se referindo a uma interação do tipo íon-van der Waals.

Em ambas as turmas, cerca de $60 \%$ dos alunos identificaram a ligação de hidrogênio, um tipo de interação à qual geralmente se atribui muita importância. A grande maioria (84\% na turma A e $77 \%$ na turma B) identificou as interações dipolo-dipolo. Porém, este número foi reduzido ao se considerar as forças de London. $\mathrm{Na}$ turma A apenas $28 \%$ a reconheceram, enquanto para a turma B este percentual foi em torno de $69 \%$ dos alunos.

Segundo o professor da turma B, uma boa revisão das forças de London foi realizada no início da disciplina, já que os estudantes costumam concebê-las apenas em alcanos de cadeia linear, esquecendo a possibilidade de que mesmo moléculas com vários grupos funcionais apresentem essas interações. As interações íon-dipolo foram pouco notadas, o que mostra que poucos estudantes consideram a presença dos íons na estrutura química apresentada. As interações íon-íon também surgiram neste item, o que mostra que os estudantes confundem este tipo de interação, sem saber se é interatômica ou intermolecular. Houve até mesmo respostas citando a interação iônica neste item.

Percebemos que muitos estudantes reconheceram apenas uma ou duas interações intermoleculares. Mesmo para estas, não podemos garantir que haja aprendizagem real, já que as interações apontadas não são as mesmas. Para exemplificar, um aluno reconheceu apenas a interação dipolo induzido, não conseguindo reconhecer a interação dipolo-dipolo, mais comum. Outro apontou apenas a ligação de hidrogênio, não citando as demais.

Os resultados observados para esse item da questão podem ser um indício de que os estudantes entram em contato com todos os tipos de interação, seja na sala de aula ou por meio da leitura de livros didáticos. Porém, tiveram dificuldade em diferenciar umas das outras e de identificar as interações presentes na molécula cuja estrutura estava representada no instrumento de coleta de dados. Novamente se fez necessário consultar o tratamento dado a este conteúdo nos livros didáticos.

\section{As interações nos livros didáticos}

Acreditamos que as dificuldades dos estudantes neste item podem ter origem na diversidade de nomes encontrados nos livros didáticos para essas interações. Eles trazem diferentes nomenclaturas para um mesmo tipo de interação intermolecular e essas informações são apresentadas em diferentes momentos nestes livros.

Atkins e Jones ${ }^{6}$ tratam de interações intermoleculares no capítulo intitulado "Líquidos e Sólidos". Nomeiam estas interações como sendo interações íon-dipolo (com o exemplo da água solvatando o cloreto de sódio), interação dipolo-dipolo, forças de London (utilizam os termos momento de dipolo induzido e dipolo instantâneo ao descrever esta força) e ligação de hidrogênio. Esta última é apresentada como um tipo de interação diferente das demais e é definida como a mais forte. O termo van der Waals é utilizado no livro inteiro apenas quando aborda as equações de estado de gases reais, não sendo empregado para tratar de forças intermoleculares.

Russel $^{7}$ não apresenta uma seção sobre forças intermoleculares e esta expressão não figura nem mesmo no índice ou no sumário do livro. No capítulo intitulado "Sólidos", aparecem os termos forças de dispersão, forças de London, forças de van der Waals e dipolodipolo, mais especificamente ao tratar dos sólidos moleculares (nos quais os pontos do retículo cristalino são moléculas). As forças entre as moléculas, chamadas de forças de van der Waals, são mais fracas que as forças entre átomos. As forças de van der Waals consideradas mais importantes são as dipolo-dipolo e as de London (ou forças de dispersão). Ao tratar sobre as forças de London o autor também usa o termo momento dipolar instantâneo.
Mahan $^{8}$ não trata das interações intermoleculares em seu livro. Não constam no índice palavras como ligação de hidrogênio, dipolo, dipolo induzido ou interações intermoleculares. Mesmo na parte que trata sobre a Química Orgânica não existe uma seção a respeito das propriedades físicas das substâncias orgânicas (onde, talvez, este tema poderia ser abordado), mostrando apenas as reações orgânicas. Isto pode ser um indício de que a atenção dispensada a este assunto seja algo recente, uma vez que tal discussão inexiste neste livro, de edição mais antiga.

No livro de Solomons e Fryhle, ${ }^{9}$ em seu segundo capítulo, intitulado "Compostos de carbono representativos: Grupos funcionais, forças intermoleculares e espectroscopia no infravermelho (IV)", na seção "Propriedades físicas e estrutura molecular", os autores discutem as forças intermoleculares. São apresentadas as forças íon-íon, forças dipolo-dipolo, ligação de hidrogênio, forças íon-dipolo e forças de van der Waals. Este livro afirma que a ligação de hidrogênio é um caso especial da interação dipolo-dipolo, na qual acontecem dipolos muito fortes que ocorrem entre átomos de $\mathrm{H}$ ligados a átomos pequenos muito eletronegativos $(\mathrm{O}, \mathrm{N}$ ou $\mathrm{F})$ e os pares de elétrons não ligantes de outros átomos eletronegativos. Assim, a ligação de hidrogênio não é um tipo diferente de interação intermolecular como propuseram Atkins e Jones, ${ }^{6}$ mas sim um caso particular de interação dipolo-dipolo. Entretanto, este livro diz que as forças de van der Waals, também chamadas forças de London ou de dispersão, são estabelecidas nos dipolos temporários, que podem induzir dipolos opostos (atrativos) nas moléculas vizinhas. Logo, diferentemente de Russel, ${ }^{7}$ que considera as forças de van der Waals como o conjunto das forças intermoleculares, estes autores consideram as forças de van der Waals como sendo apenas as originadas pelos dipolos instantâneos, excluindo aquelas geradas pelos dipolos permanentes.

Smith e March ${ }^{10}$ expõem esta questão de forma objetiva. Alegam que forças atrativas entre moléculas são mais fracas e são denominadas forças de van der Waals, sendo causadas por atrações eletrostáticas como dipolo-dipolo e dipolo induzido-dipolo induzido.

Observamos que diferentes autores usam nomenclaturas diferenciadas para uma mesma interação. Uma hipótese para justificar estas diferenças poderia ser direcionada para a tradução feita. É possível que, no momento da tradução, o responsável tenha cometido alguns equívocos. No entanto, são esses os livros que os estudantes de graduação utilizam, ao cursarem disciplinas como Química Geral e Química Orgânica e o fato de não serem padronizados pode estar colaborando para que estudantes confundam as diferentes interações.

\section{Estrutura de Lewis}

O terceiro e último item da questão solicitava que os alunos desenhassem a estrutura de Lewis dos grupos nitro $\left(\mathrm{NO}_{2}\right)$ presentes na estrutura da Figura 1. Esperávamos que os estudantes representassem esta estrutura se aproximando da representação presente na Figura 2.

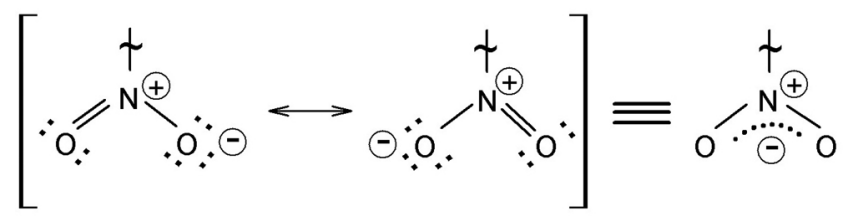

Figura 2. Estrutura esperada para a representação da estrutura de Lewis dos grupos nitro $\left(\mathrm{NO}_{2}\right)$

\section{As respostas dos estudantes}

Para esta questão as respostas foram inicialmente classificadas como corretas ou incorretas. Porém em alguns casos, os alunos desenharam a estrutura com o compartilhamento de elétrons correto, mas 
não escreveram as cargas. Para esta situação foi criada a classificação "estrutura com compartilhamento de elétrons correto, mas sem carga". Tais respostas estão apresentadas na Tabela 3.

Tabela 3. A representação de Lewis para os grupos nitro, segundo os estudantes

\begin{tabular}{lcc}
\hline Resposta & Turma A & Turma B \\
\hline Estrutura totalmente correta & $12(48 \%)$ & $3(23 \%)$ \\
$\begin{array}{l}\text { Estrutura com compartilhamento de elétrons } \\
\text { correto, mas sem carga }\end{array}$ & $2(8 \%)$ & $2(15 \%)$ \\
Estrutura incorreta & $11(44 \%)$ & $8(62 \%)$ \\
\hline
\end{tabular}

Para exemplificar, selecionamos um desenho cuja representação de Lewis classificamos como "estrutura com compartilhamento de elétrons correto, mas sem carga" (Figura 3) e um que classificamos como incorreto (Figura 4).

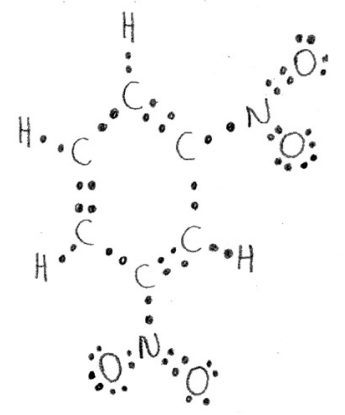

Figura 3. Estrutura de Lewis com compartilhamento de elétrons correto, mas sem carga

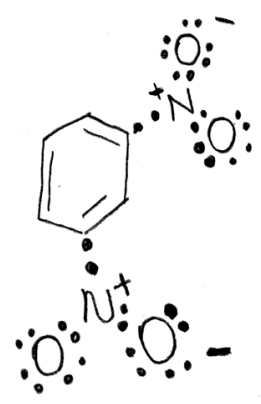

Figura 4. Estrutura de Lewis desenhada incorretamente

Na Figura 3 podemos observar a ausência de cargas no oxigênio dos dois grupos nitro. Na Figura 4, os nitrogênios estão representados com 6 elétrons e, apesar da presença das cargas, o estudante manteve o número de elétrons dos oxigênios definidos pela regra do octeto. Ao que nos parece, o uso excessivo da regra do octeto não permitiu ao estudante construir corretamente a estrutura de Lewis.

Nesta questão consideramos o resultado como um indício importante de que, muitas vezes, os estudantes não conseguem propor e avaliar uma geometria molecular por não conseguirem construir adequadamente a estrutura de Lewis de alguma substância, principalmente quando se trata de uma estrutura com muitos átomos. A porcentagem de acerto da estrutura de Lewis foi baixa, mesmo se considerarmos as estruturas com compartilhamento de elétrons, mas sem cargas. Estudos de Cooper e colaboradore ${ }^{11}$ também relatam as dificuldades dos estudantes graduados e graduandos em Química, do sudoeste dos Estados Unidos, em desenhar as estruturas de Lewis. Neste estudo, os autores afirmam que os estudantes tendem a bus- car a simetria na representação da estrutura de Lewis mais estável. Sobre as cargas, os pesquisadores afirmam que os estudantes, ao representarem a estrutura de Lewis, tendem a deixar as cargas para o final, preocupando-se primeiro com a estrutura. Provavelmente esta mesma tendência levou muitos de nossos estudantes pesquisados a esquecerem ou errarem as cargas. No estudo de Cooper e colaboradores, ${ }^{11}$ um dos principais motivos que levou estudantes a errarem a estrutura de Lewis foi o uso exagerado da regra do octeto. Estes autores comentam casos nos quais os estudantes vislumbram como única alternativa acrescentar elétrons à estrutura até atingir o octeto em todos os átomos. Para isso, usam como exemplo a molécula NO, para a qual os estudantes pesquisados creditam 12 elétrons ao invés dos 11 disponíveis. No estudo de Fields, ${ }^{12}$ a autora mostra que estudantes se baseiam na regra do octeto para determinar como os elétrons estão distribuídos ao redor do átomo, na molécula e que apenas após uma reorientação no desenho e o auxílio do professor é que foram capazes de fazer a estrutura de Lewis. Porém, a pesquisadora afirma que os estudantes não apresentavam um claro entendimento do que estavam fazendo. ${ }^{12}$

\section{A estrutura de Lewis nos livros didáticos}

Estrutura de Lewis é um tema bastante presente tanto nos livros de Química Geral quanto nos livros de Química Orgânica. Em geral, os livros apresentam regras para montar a estrutura de Lewis de um composto. Para algumas moléculas é possível atribuir cargas formais para determinados átomos, dependendo de como estão ligados, ou seja, como seus elétrons estão distribuídos. Consideramos que a estrutura de Lewis também é uma boa ferramenta para analisar o entendimento de ligações químicas, além de ser de vital importância para a Química Orgânica. De maneira geral, podemos afirmar que o tratamento dado a este assunto, nos diferentes livros didáticos, é semelhante.

Na turma A o percentual de acerto foi praticamente metade, enquanto na turma B um maior percentual de estudantes errou a representação solicitada. Considerando que estes alunos já cursaram algumas disciplinas específicas da Química e, entre elas, a Química Geral, percebemos que muitos deles não representaram a estrutura de Lewis para os grupos nitro, conforme é indicado nos livros.

Cooper e colaboradores ${ }^{11}$ afirmam que os estudantes aprendem pouco sobre estrutura de Lewis em função de, sendo este um assunto complexo, não perceberem a potencial utilidade das mesmas para o entendimento de ligações, interações, propriedades, entre outros assuntos importantes da Química. Acreditamos que este também pode ser o motivo que faz com que os estudantes investigados neste trabalho apresentem pouca aprendizagem sobre este assunto.

\section{CONSIDERAÇÕES FINAIS}

A análise do questionário mostra que parte considerável de alunos, mesmo estando ao final da disciplina de Química Orgânica, ainda tem dificuldades em compreender conceitos básicos importantes para uma boa formação em Química. Mesmo tendo passado por disciplinas básicas do curso, que costumam fazer revisão de conceitos que serão necessários ao longo do curso, para o entendimento do mundo sob o ponto de vista da Química, alguns estudantes ainda não se apropriaram deles.

Os livros didáticos talvez estejam contribuindo para que os estudantes formem concepções alternativas referentes aos conceitos de ligação e interações. É provável que estes alunos consigam atingir a pontuação necessária para a aprovação na disciplina de Química Orgânica 1, na qual desenvolvemos este trabalho. Porém, certamente continuarão apresentando dificuldades nos conteúdos e disciplinas subsequentes, já que não se apropriaram devidamente dos conceitos básicos. 
Mesmo que não tenhamos nos detido nas causas, sabemos que alguns alunos não estão aprendendo conteúdos importantes e estão avançando no curso sem este conhecimento. No caso dos estudantes de Química, ao se tornarem professores, estarão reproduzindo de maneira equivocada os conceitos dos quais não se apropriaram, criando um círculo vicioso e ineficaz na formação dos sujeitos. Acreditamos que valeria a pena repensar o ensino destes conceitos na graduação, tanto em termos de facilitar a aprendizagem como em termos de materiais didáticos disponíveis.

Foi apontado que o ensino universitário ainda é muito tradicional e tecnicista, mantendo um vínculo forte com o modelo de transmissão/recepção. Mesmo hoje, após tantos debates sobre o ensino e até diante de diretrizes curriculares apresentando novas orientações, a dificuldade em implementar tais orientações pode ter justificativas diversas. Entre elas podemos citar o fato de que muitos professores universitários não tiveram contato mais sistemático com teorias de ensino e aprendizagem, da pressão que o ambiente universitário exerce em torno da pesquisa e da publicação, da organização da universidade em torno dos departamentos e não do curso que forma estudantes, entre outras. ${ }^{13}$ As teorias de ensino e aprendizagem, advindas principalmente da Psicologia, oferecem ferramentas importantes para o entendimento do que acontece na sala de aula. O uso da História da Química ${ }^{14}$ pode ser uma ferramenta adequada para justificar determinados conceitos científicos para os alunos. Massi ${ }^{15}$ argumenta que o uso de artigos científicos se constitui numa ferramenta importante para o Ensino Superior de Química, ajudando a desenvolver nos estudantes habilidades de pesquisa dentro da literatura científica e, também, as habilidades de comunicação e de expressão. Também acreditamos que a contextualização e a necessária descontextualização progressiva, assim como a interdisciplinaridade, tão discutidas na educação básica, possam se estender ao Ensino Superior.

Para além das várias ferramentas didáticas e diversas abordagens de ensino que existem, pensamos que o mais importante, como também afirma Maldaner, ${ }^{16}$ é que haja um processo de autorreflexão de nossa atividade profissional, buscando sempre estabelecer um ensino de qualidade.

\section{REFERÊNCIAS}

1. Diário Oficial da União, 23 dezembro de 1996, p. 248.

2. http://www.abepsi.org.br/web/linha_do_tempo/memoria/docs/ fr_1997_6.htm, acessada em Julho 2011.

3. Zucco, C.; Pessine, F. B. T.; de Andrade, J. B.; Quim. Nova 1999, 22, 454.

4. Schnetzler, R. P. Em Ensino de Ciências: fundamentos e abordagens; Schnetzler, R. P.; Aragão, R. M. R., eds.; $1^{\text {a }}$ ed.; Capes/Unimep: Piracicaba, 2000, cap. 2.

5. Maldaner, O. A.; Schnetzler, R. P. Em Ciência, Ética e Cultura na Educação; Chassot, A.; Oliveira, J. R., eds.; Editora UNISINOS: São Leopoldo, 1998, cap 3.

6. Atkins, P.; Jones, L.; Princípios de Química: Questionando a vida moderna e o meio ambiente, Bookman: Porto Alegre, 2001.

7. Russel, J.; Química Geral, 2ª ed., Makron Book: São Paulo, 1994, vol. 1.

8. Mahan, B.; Química: Um curso universitário, Editora Edgard Blucher Ltda: São Paulo, 1970.

9. Solomons, T. W.; Fryhle, C. B.; Química Orgânica, 8ª ed., LTC: Rio de Janeiro, 2005, vol. 1.

10. Smith, M.; March, J.; March's Advanced Organic Chemistry: Reactions, mechanisms, and structure, $5^{\text {th }}$ ed., Wiley InterScience: New York, 2001.

11. Cooper, M. M.; Grove, N.; Underwood, S. M.; Klymbowsky, M. W.; J. Chem. Educ. 2010, 87, 869.

12. Fields, A. G.; Tese de Doutorado, Ball State University, Estados Unidos, 1998.

13. Quadros, A. L.; Tese de Doutorado, Universidade Federal de Minas Gerais, Brasil, 2010.

14. Oki, M. C. M.; Moradillo, E. F.; Ciência \& Educação 2008, 14, 67; Chassot. A. I.; Presença Pedagógica 1999, 5, 64; Justi, R. S.; Química Nova na Escola 1998, n 7, 26.

15. Massi, L.; Santos, G.; Ferreira, J.; Queiroz, S. L.; Quim. Nova 2009, 32, 503.

16. Maldaner, O. A.; A formação inicial e continuada de professores de química, 3ª ed., Ed. Unijuí: Ijuí, 2006. 